\title{
ОБ ОБРАЗОВАНИИ ПРОВАЛОВ НА УЧАСТКЕ АВАРИИ 1995 ГОДА НА РУДНИКЕ СКРУ-2
}

\author{
С.Ю. ДЕВЯТКОВ \\ Горный институт УрО РАН, г. Пермь
}

\begin{abstract}
Аннотация: Рассмотрена ситуация на участке массового обрушения междукамерных целиков на руднике СКРУ-2, в результате которого образовалась мульда сдвижения с высокими градиентами оседаний в ее краевых частях. Средствами математического моделирования исследовано состояние породного массива перед образованием провала на земной поверхности. Показана необходимость введения в геомеханическую модель в интервале надсоляной толщи областей, ослабленных по прочностным и деформационным свойствам пород. Данные области, позволяют точнее описывать протекающие в массиве процессы деформирования, а их существование подтверждается по результатам сейсморазведочных работ. На основе критериальной оценки состояния подработанного массива установлено его критическое состояние и вероятное нарушение сплошности водозащитной толщи вследствие образования сквозной зоны трещиноватости. Показана развитие субвертикальной зоны техногенной нарушенности от земной поверхности до выработанного пространства, что указывает на возможность перехода статических оседаний в динамическую форму с последующим образованием провала на земной поверхности.

Ключевые слова: сдвижение, оседание земной поверхности, провалы, надсоляная толща, напряженно-деформированное состояние, разрушение водозащитной толщи, математическое моделирование
\end{abstract}

\section{Введение}

5 января 1995 г. в районе г. Соликамск произошло землетрясение, максимальная интенсивность которого достигала 5 баллов [1]. Эпицентральная зона находилась в краевой части шахтного поля рудника СКРУ-2. С землетрясение были связаны массовые разрушения междукамерных целиков и обрушения кровли рабочих пластов на площади $600 \times 600$ м (рис. 1). Вследствие этого на земной поверхности образовалась мульда с размерами в плане $650 \times 850$ м и максимальными оседаниями до 4,5 м [2]. Кроме того, были осушены озеро и ближайшие родники.

Несмотря на то, что по результатам комплексных сейсмогеомеханических исследований, проведенных на месте аварии, были выявлены обширные зоны нарушения водозащитной толщи (В3Т), поступление надсолевых вод в рудник зафиксировано не было. Во многом это связано с особенностями геологического строения породного массива в районе обрушения: по всей видимости, мощные глинистые прослойки в надсоляной толще, заполнив собой трещины в породе, заблокировали доступ пресных вод в горные выработки. После этого ситуация в целом оставалась стабильной на протяжении почти 20 лет.

В сентябре 2014 г. в районе юго-восточной границы зоны обрушения (рис. 1) было зафиксировано резкое увеличение сейсмической активности [3], а уже в ноябре - прорыв надсолевых вод в горные выработки. Вечером 18 ноября был обнаружен провал на земной поверхности. По результатам видеосъёмки с воздуха, размеры провала составили: в коренных породах - 25x54 м, в рыхлых отложениях на уровне земной поверхности - 50х80 м.

2 мая 2018 г. северо-западнее провала 2014 г. произошло образование еще одной воронки с первоначальными размерами $25 \times 30$ м.

По результатам сейсмологического мониторинга аварийного участка образование провалов сопровождалось всплеском сейсмической активности. В 2014-2018 гг. её эпицентр находился в юго-восточной части зоны обрушения, где в этот период произошло образование двух провалов. В настоящее время наибольшее количество сейсмических событий фиксируется в северо-западной части.

Начиная с 1996 г., на аварийном участке в ежегодном режиме выполняются комплексные сейсмогеомеханические исследования, включающие сейсморазведочные работы и, основанный на полученных данных, анализ состояния ВЗТ. 


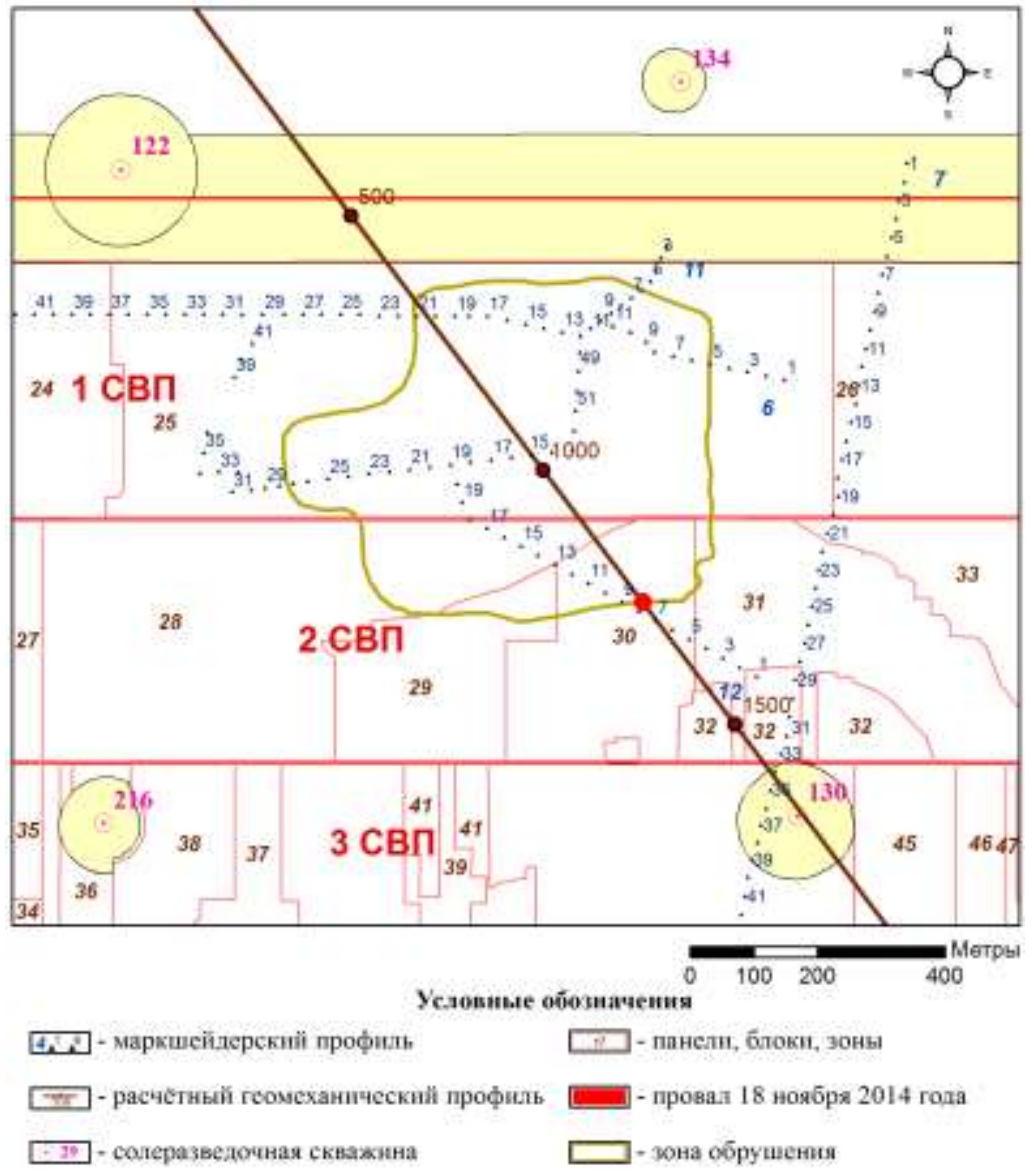

Рис. 1. Обзорная схема места аварии

Целью настоящих исследований является оценка методами многовариантного математического моделирования напряженно-деформированного состояния (НДС) подработанного массива в условиях формирования мульд сдвижения с высокими градиентами оседаний земной поверхности, предшествующих образованию провалов.

\section{Постановка задачи}

Расчеты НДС породного массива осуществлялись в упругопластической постановке для условий плоского деформированного состояния методом конечных элементов $[4,5]$.

Расчётный геомеханический профиль (рис. 1) пересекает исследуемый район с северо-запада на юго-восток, проходя через центральную часть зоны обрушения 1995 г. и места образования провала на земной поверхности в 2014 г. В пределах района исследований в 1970/80-х годах отработаны сильвинитовые пласты АБ, КрII и В

Принципиальная геомеханическая расчетная схема представлена на рис. 2.

При математическом моделировании учитывались основные особенности строения массива, действие массовых сил, интенсивностью $\gamma_{i}\left(\gamma_{i}\right.$ - удельный вес пород $i$-го элемента геологического разреза. Граничные условия формулировались из следующих соображений: верхняя граница (земная поверхность) принималась свободной; выбранные размеры исследуемой области обеспечивали равенство нулю на нижней границе вертикальных, а на боковых границах - вертикальных перемещений.

Выработанное пространство моделировалось средой с пониженными по отношению к породам вмещающего пласта свойствам. Степень уменьшения механических свойств определялась фактическими параметрами камерной системы разработки.

Выполненные в 1995 году натурные исследования состояния междукамерных целиков на участке, прилегающем к зоне аварии, показали снижение их несущей способно- 
сти на расстоянии до 95-110 метров от границы зоны обрушения. Данное обстоятельство отражалось в расчетной схеме путем уменьшения эффективных свойств отработанных пластов в пределах стометровой зоны.

Результаты геомеханического анализа сложившейся ситуации в районе аварии контролировались фактическими сдвижениями земной поверхности.

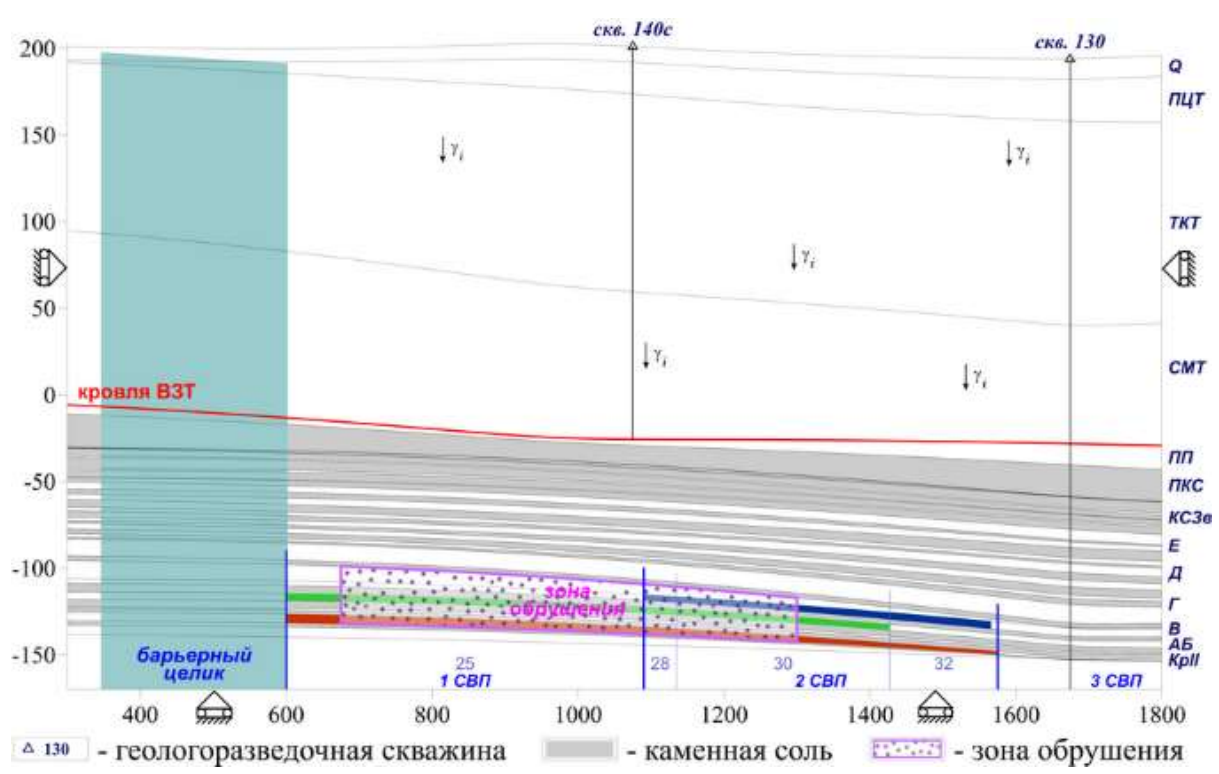

Рис. 2. Принципиальная расчётная схема

\section{Анализ результатов математического моделирования}

На рис. 3 показаны оседания земной поверхности вдоль расчётного геомеханического профиля на момент времени предшествующий образованию провала на земной поверхности (ноябрь 2014 года). Здесь также показаны оседания по данным маркшейдерских измерений по реперам, находящимся вдоль расчётного профиля. Как видно, между фактическими и расчетными оседаниями наблюдается приемлемое согласование, что свидетельствует об адекватности результатов математического моделирования реальным процессам деформирования породного массива.

Мульда сдвижения имеет достаточно симметричных вид с высокими градиентами оседаний в краевых частях. Максимальные оседания земной поверхности достигаются в центральной части зоны обрушения. Наблюдаемый характер мульды сдвижения предопределяет высокую техногенную нагрузку на подработанный массив в краевых частях зоны обрушения 1995 г.

На рис. 4 представлен характер техногенной нарушенности породного массива на момент образования провала на земной поверхности. Расчёты показывают, что субвертикальные зоны техногенной нарушенности ВЗТ формируются в краевых частях зоны обрушения 1995 г. и приурочены к перегибам мульды сдвижения. При этом можно заметить, что в отличии от юго-востока, где в ВЗТ фактически наблюдается сквозная область разрушения, на северозападе целостность ВЗТ сохраняется за счёт пластов каменной соли, ПКС и ПП.

Необходимо отметить, что данные результаты получены без учета аномалий, выявленных по результатам сейсморазведочного мониторинга аварийного участка. Поскольку сейсморазведочные аномалии в расчетах учитываются как области с пониженными, в соответствии с установленным коэффициентом ослабления, прочностными и деформационными свойствами пород, можно утверждать, что, даже при самых благоприятных условиях к ноябрю 2014 г. в юго-восточной части зоны обрушения 1995 г. в ВЗТ могла сформироваться сквозная область техногенной нарушенности. 


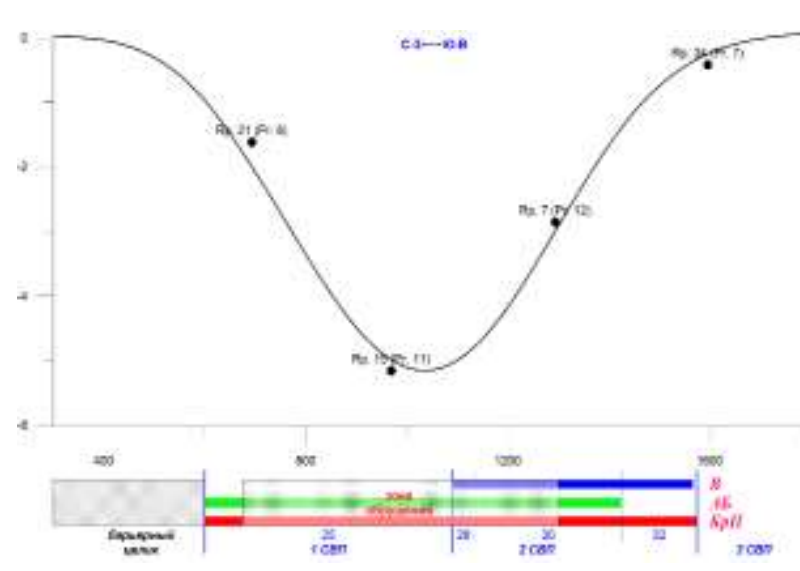

Рис. 3. Оседания земной поверхности (ноябрь 2014 г.)

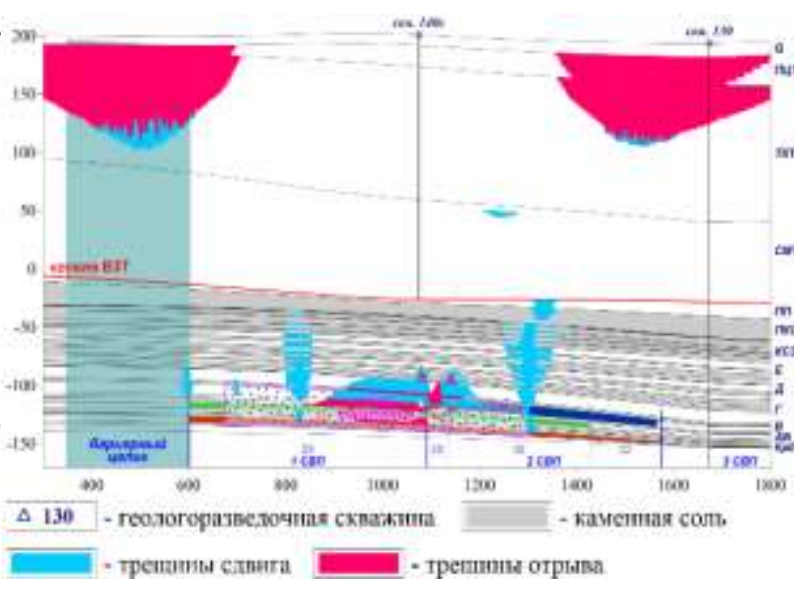

Рис. 4. Характер техногенного нарушения сплошности массива

Снижение механических свойств пород в пределах сейсморазведочных аномалий априори ведет к увеличению техногенной нагрузки на породный массив. На рис. 5 представлен характер техногенной нарушенности породного массива при различных коэффициентах ослабления в выделенных в ВЗТ аномалиях.

По результатам математического моделирования установлено, что даже при незначительном снижении прочностных и деформационных свойств в аномалии II происходит образование в ВЗТ сквозной зоны техногенной нарушенности в юго-восточной части зоны обрушения (рис. 5 , а). При этом с увеличением коэффициента ослабления наблюдается расширение зоны техногенной нарушенности по латерали (рис. 5, а-г). При коэффициенте 1,4, соответствующему результатам сейсморазведочных работ, размеры области достигают 100 м в кровли ВЗТ и 200-250 м в верхних карналлитовых пластах.

В тоже время несколько иная картина наблюдается в северо-западной части расчётного профиля (рис. 5). Здесь уже при ослаблении механических свойств пород в 1,1 раза происходит образование трех несвязанных между собой субвертикальных зон техногенной нарушенности с сохранением целостности пластов каменной соли, ПКС и ПП (рис. 5, а). При большем коэффициенте ослабления зоны расширяются по латерали и соединяются, образуя единую область техногенной нарушенности порядка 350 м по латерали (рис. 5, б-г). При этом целостность ВЗТ сохраняется.

Таким образом, на ноябрь 2014 года в юго-восточной части зоны обрушения в В3Т сформировалась сквозная зона техногенной нарушенности, которая могла служить каналом проникновения надсолевых вод в выработанное пространство рудника. В северозападной части зоны обрушения при заданном уровне снижения механических свойств в сейсморазведочной аномалии (1,4 раза) целостность В3Т сохранялась только за счет ПКС и ПП. В нижележащих породах наблюдается обширная (до 350 м) область субвертикальной трещиноватости.

При дальнейших расчётах предполагается, что над сквозной зоной трещиноватости в В3Т, являющейся потенциальным каналом проникновения надсолевых вод в горные выработки, существует ослабленная по прочностным и деформационным свойствам область, образующаяся вследствие притока вод к зоне трещиноватости.

Введение данных областей также позволяет добиваться заметно лучшего соответствия расчётных и наблюдаемых оседаний земной поверхности. В случае же высоких градиентов оседаний в краевых частях мульды сдвижения, их обеспечение, согласно геомеханическим расчетам $[6,7]$, может оказаться невозможным без введения в расчетную схему ослабленной по прочностным и деформационным свойствам области в интервале верхней части геологического разреза. 

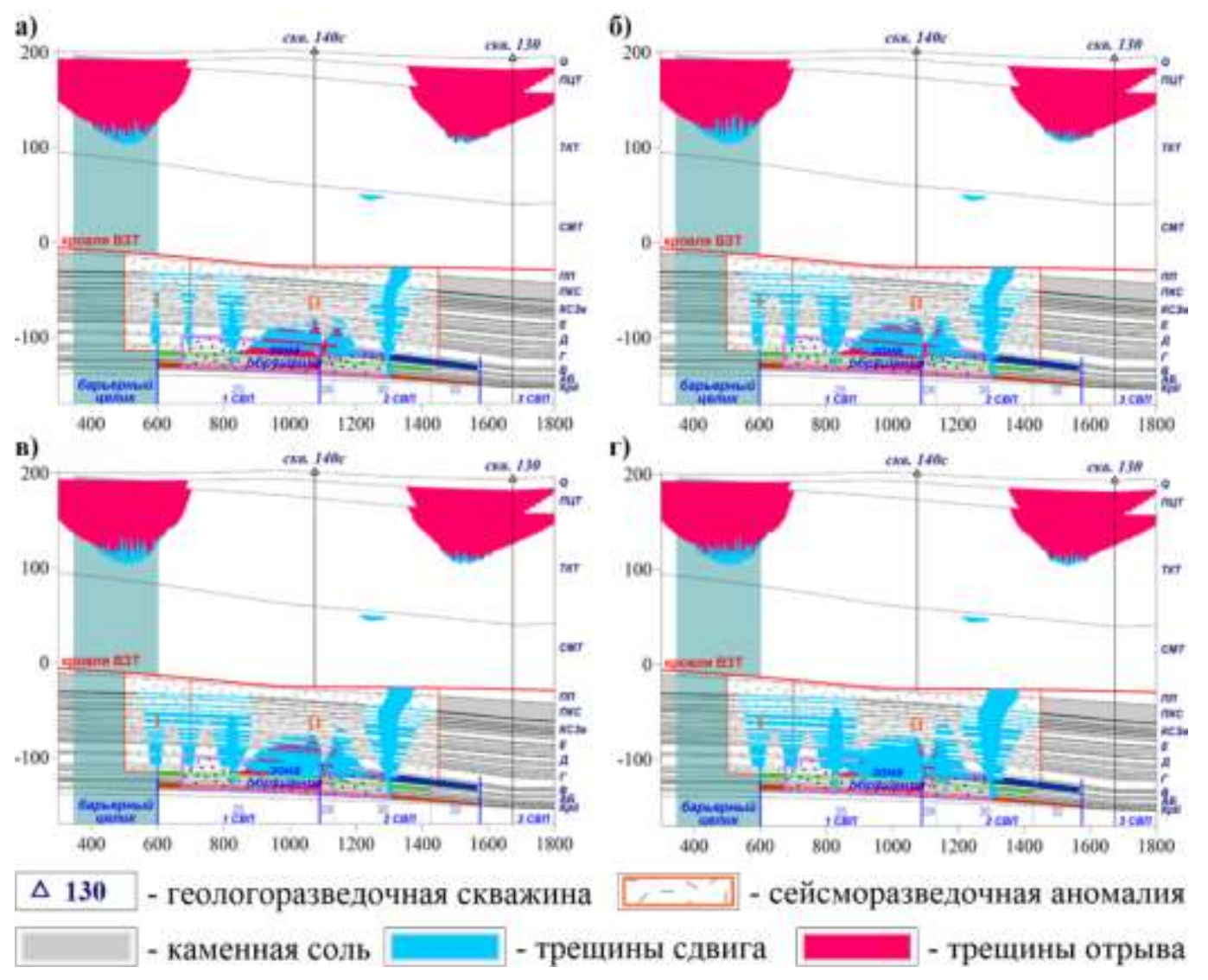

Рис. 5. Характер техногенного нарушения сплошности породного массива при коэффициенте ослабления в сейсморазведочных аномалиях:

a) 1,1 ; б) 1,2 ; в) 1,3 ; г) 1,4

На рис. 6 представлены оседания земной поверхности в случае включения в расчётную схему «ослабленных» областей в интервале надсоляной толщи, которые были добавлены в краевых частях зоны обрушения 1995 г. Хорошо видно, что по сравнению с расчётами без «ослабленных» областей (пунктирная линия), оседания в этом случае (сплошная линия) точнее соответствуют данным маркшейдерских измерений сдвижений земной поверхности. Существование подобных «ослабленных» областей в породном массиве подтверждается по результатам сейсморазведочных работ, что делает их включение в расчетную схему полностью обоснованным.

В соответствие с выполненными критериальными оценками состояния подработанного массива, в случае существования над водопроводящими каналами в ВЗТ «ослабленных» областей в них появляются зоны техногенной трещиноватости (рис. 7). При уменьшении механических свойств пород в этих областях в 3 раза образуется сквозная зона техногенной нарушенности от земной поверхности до кровли В3Т, а с учётом полного разрушения ВЗТ - до выработанного пространства рудника.

В рамках рассматриваемой модели, данный результат математического моделирования указывает на возможность перехода в юго-восточной части зоны обрушения статических оседаний в динамическую форму с образованием провала на земной поверхности в случае существования в массиве полости, достаточной для вмещения обрушенных пород [8].

В северо-западной части зоны обрушения также формируются обширные области техногенной нарушенности пластов ВЗТ. И несмотря на то, что формально тут нет сквозной области трещиноватости, состояние породного массива на данном участке можно тоже считать потенциально опасным. 


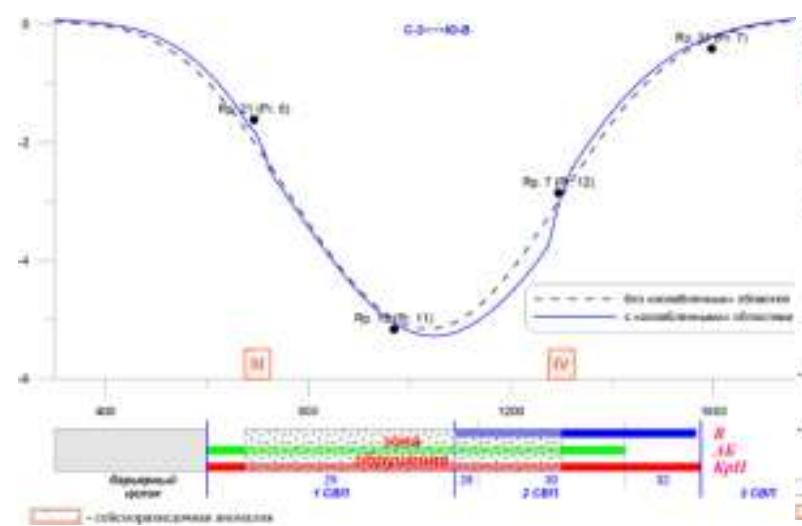

Рис. 6. Оседания земной поверхности при наличии «ослабленных» областей в надсоляной толще

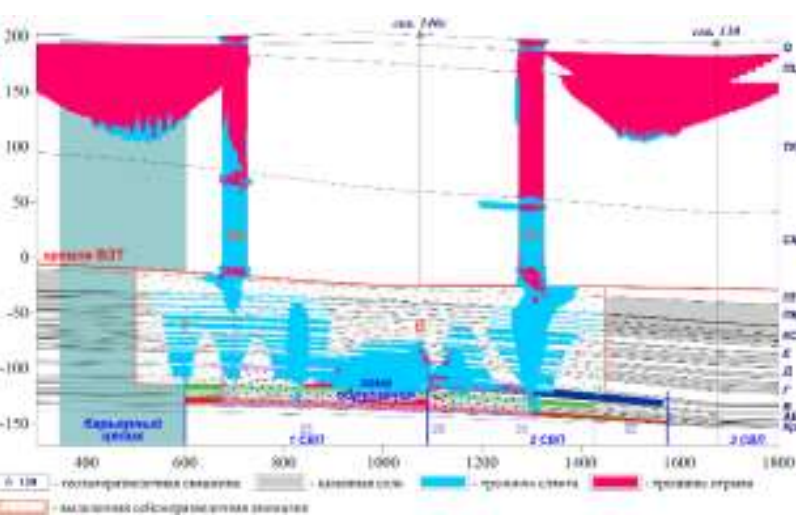

Рис. 7. Критериальная оценка состояния массива при наличии «ослабленных» областей в надсоляной толще

\section{Выводы}

Сформировавшиеся в результате аварии 1995 г. зоны техногенной нарушенности породного массива на границах зоны обрушения, позволили реализоваться на земной поверхности мульде сдвижения с высокими градиентами оседаний в ее краевых частях. Несмотря на то, что в пределах зоны обрушения после аварии в течении почти 20 лет наблюдались небольшие скорости оседаний земной поверхности, наличие зон техногенной нарушенности и негативная динамика их развития во времени, выявленная по результатам сейсморазведочных работ, привели к возникновению фактически сквозных областей разрушения от земной поверхности до выработанного пространства рудника и дальнейшему увеличению градиента оседаний.

По всей видимости, формирование мульд сдвижения с высокими градиентами оседаний, наблюдаемыми на небольших участках шахтного поля, может служить индикатором разрушения пород надсоляной толщи. Включение данных областей нарушенности пород в расчетную схему при математическом моделировании позволяет существенно точнее согласовывать расчетные и фактические оседания земной поверхности. Для более точной критериальной оценки состояния породного массива пространственная локализация «ослабленных» областей и уровень снижения механических свойств в них требуют подтверждения результатами сейсморазведочных исследований.

\section{БИБЛИОГРАФИЧЕСКИЙ СПИСОК}

1. Маловичко А.А., Маловичко Д.А., Кустов А.К. Соликамское землетрясение 5 января 1995 года (Ms = 4.2) // Землетрясения Северной Евразии в 1995 году. / ГС РАН. - М., 2001. - С. 163-169.

2. Барях А.А., Санфиров И.А., Еремина Н.А., Бабкин А.И., Сабиров Р.Х., Гилев М.В., Мынка Ю.В. Контроль за развитием аварийных ситуаций на калийных рудниках // Горн. вестн. - 1997. - № 6. - С. 91-101.

3. Шулаков, Д.Ю., Варлашова Ю.В. Сейсмологический мониторинг развития аварийной ситуации на руднике СКРУ-2 // Современные методы обработки и интерпретации сейсмологических данных: материалы Десятой Междунар. сейсмологич. шк. / ГС РАН. - Обнинск, 2015. - С. 368-372.

4. Зенкевич О. Метод конечных элементов в технике / О. Зенкевич. - М.: Мир, 1975. - 541 с.: ил.

5. Фадеев А.Б. Метод конечных элементов в геомеханике. - М.: Недра, 1987. - 221 с.: ил.

6. Девятков С.Ю. К вопросу определения условий формирования провалов на земной поверхности // Стратегия и процессы освоения георесурсов: сб. науч. тр. Вып. 12 / ГИ УрО РАН. - Пермь, 2014. C. $96-98$.

7. Барях А.А. Теоретическое обоснование условий образования провалов на земной поверхности после аварийного затопления калийных рудников / А.А. Барях, С.Ю. Девятков, Н.А. Самоделкина // Физикотехнические проблемы разработки полезных ископаемых. - 2016. - № 1. - С. 50-61.

8. Барях А.А., Девятков С.Ю. Геомеханическая оценка условий образования провалов на земной поверхности на участке прорыва пресных вод в калийный рудник // Горн. журн. - 2018. - № 6. - С. 17-21. 